\title{
Drug therapy of advanced cutaneous squamous cell carcinoma: is there any evidence?
}

\author{
Simone Ribero ${ }^{\mathrm{a}}$, Luigia Stefania Stucci ${ }^{\mathrm{b}}$, Gregory A. Daniels ${ }^{\mathrm{c}}$, and \\ Luca Borradorid
}

\begin{abstract}
Purpose of review
There are few randomized controlled studies to guide the treatment of advanced cutaneous squamous cell carcinoma. The existing treatments are mostly based on case reports and small case series. Here we review recently available insights concerning the treatment of locally advanced and metastatic squamous cell carcinoma, with a special emphasis on novel targeted therapy and immunotherapy.
\end{abstract}

\begin{abstract}
Recent findings
Surgery and combination of chemotherapy and radiation therapy have been long considered the gold standard options for advanced squamous cell carcinoma. The detection of clinically relevant driver mutations has opened the door to the use of novel targeted therapies. Recent studies have shown that aggressive cutaneous squamous cell carcinoma is characterized by a very high mutational background. Furthermore, the importance of the defective immunosurveillance in the growth of cutaneous squamous cell carcinoma and the critical role of programed cell death protein 1 and programmed death-ligand 1 interaction in skin tumor development provides a rationale for the use of immune checkpoint inhibitors.
\end{abstract}

\section{Summary}

Epidermal growth factor receptor inhibitors have shown to have satisfactory antitumor activity with acceptable side-effect profile. However, their place in management of advanced cutaneous squamous cell carcinoma alone or in combination with either radiation therapy and/or chemotherapy needs to be better characterized. The available preliminary findings suggest that immune checkpoint inhibitors represent a potentially valuable alternative in cutaneous aggressive squamous cell carcinoma, promising a further expansion of their indication spectrum. Randomized controlled studies will allow us to better characterize their practical value.

\section{Keywords}

antiepidermal growth factor receptor, cutaneous squamous cell carcinoma, immune checkpoint inhibitors, immunotherapy, metastasis

\section{INTRODUCTION}

Cutaneous squamous cell carcinomas (cSCC) represent the second most-frequent skin cancer [1]. cSCC are associated with significant morbidity and are responsible for the majority of nonmelanoma skin cancer (NMSC) deaths. Several risk factors for recurrence and metastasis have been identified, such as large tumor diameter, poor histological differentiation and immunosuppression [2].

Definitive management of early or small cSCC primarily relies on local therapies including topical agents, thermal ablation, surgical resection or radiation. However, in cases of locally advanced inoperable disease and metastatic disease, palliative radiotherapy and/or classical chemotherapies can offer modest clinical benefit. There is a critical need for improved treatments in advanced cSCC patients.
Two general approaches that have made substantial improvements in systemic agents in oncology have been the use of molecular targeted agents and immune modulation. Epidermal growth factor receptor (EGFR) and its family members are often

\footnotetext{
${ }^{a}$ Department of Medical Sciences, Section of Dermatology, University of Turin, Turin, ${ }^{\mathrm{b}}$ Department of Biomedical Sciences and Human Oncology, University of Bari Aldo Moro, Bari, Italy, "Moores Cancer Center, University of California, San Diego, San Diego, California, USA and dDepartment of Dermatology, University of Bern, Inselspital, Berne, Switzerland

Correspondence to Luca Borradori, MD, Department of Dermatology, Inselspital University Hospital and University of Berne, Freiburgstrasse 18, CH-3010 Bern, Switzerland. E-mail: luca.borradori@insel.ch
}

Curr Opin Oncol 2017, 29:129-135

DOI:10.1097/CCO.0000000000000359 


\section{KEY POINTS}

- The gold standard options for locally advanced inoperable cutaneous squamous cell carcinoma have been chemotherapy and/or radiation therapy, but the overall responses are often poor and unsatisfactory.

- EGFR inhibitors have been increasingly used for advanced cutaneous squamous cell carcinoma and have shown antitumor activity.

- There is a strong biological rationale for the use of immune checkpoint inhibitors, such as anti-PD-1 antibodies in advanced squamous cell carcinoma. The preliminary results are encouraging but need to be confirmed in controlled studies.

overexpressed or activated in human carcinomas including cSCC and may contribute to enhance uncontrolled proliferation. Anti-EGFR therapies have clinical benefit alone or in combination with chemotherapy and radiotherapy. The rat sarcoma viral oncogene homolog-mitogen-activated protein kinases signaling pathway, which is involved in regulating growth and proliferation of cSCC, represents another new potential therapeutic target.

Current immune modulation strategies attempt to generate a new antitumor response or to allow a natural immune response to control tumor growth. The development of cSCC is critically affected by a defective immune surveillance with lack of tumorreactive T cells suggesting a role for immune control of these tumors [3]. Recent studies have indicated that cSCC is highly mutated, displaying a complex genetic background [4"']. Blocking either CTLA-4 or programed cell death protein 1/programmed deathligand 1 (PD-1/PD-L1) on $\mathrm{T}$ cells generates antitumor responses taking advantage of tumor mutations or 'neoantigens'. Finally, certain types of cSCC express PD-L1 and transgenic mice overexpressing PD-L1 in the epidermis exhibit accelerated development of cSCC [5]. In this context, immune checkpoint antibodies that block the PD-1/PD-L1 pathway and thereby increase the T-cell-specific immune response represent a novel promising therapeutic approach, which has been anecdotally used with encouraging preliminary results.

\section{EPIDEMIOLOGY}

Since the 1960s, the worldwide incidence of NMSC has been constantly increasing. Fair-skin individuals living in countries close to the equator and tropics are the most commonly affected patients. In fact, exposure to ultraviolet (UV) radiation and sunlight represent the greatest risk factors for the development of cSCC with a clear mutational signature of UV radiation [6]. Australia has the highest incidence in the world, with over 300000 patients diagnosed per year. One study has estimated a diagnosis rate of 15-35 cSCC per 100000 people, with an average increase of $2-4 \%$ per year [7]. In the United States, up to 420000 new cases of cSCC have been estimated to occur in 2012 [8]. Although only 5\% will become locally advanced, recur or metastasize, this still represents a significant problem (Figs 1 and 2). Their overall fatality rate is estimated between 1 and 5\%. A large study reviewing 603 patients with metastatic cSCC found that $89 \%$ of patients with distant metastasis died of their disease at 5 years $[9,10]$.

\section{AVAILABLE TREATMENTS: OVERVIEW}

Therapeutic options for cSCC include surgery, radiotherapy, chemotherapy, electrochemotherapy [11], targeted pharmacologic therapy and/or immunotherapy. Treatment of cSCC depends on the involvement of regional lymph nodes, distant metastasis and/or inoperable metastatic disease [12]. However, there is currently no clear standard of care for locally advanced unresectable and metastatic cSCC. Furthermore, the general condition of the patient, patient's age, associated comorbidities and immunosuppression state are important variables that should be considered for appropriate management [13].

Current management of regional spread (draining lymph node basin) is surgical excision with consideration of adjuvant radiation [14,15"']. Surgery may be performed in patients with metastasis when tumor characteristics (i.e. size, location and number) allow for complete removal at or near the primary tumor site [15"']. However, improved local disease control may be achieved when radiotherapy is used in combination with surgery. Veness et al. [16] assessed the results obtained in 167 patients over a 20-year period. Their findings indicate that patients undergoing combined treatment had a lower rate of locoregional recurrence as well as a significantly better 5-year disease-free survival rate compared with surgery alone [16]. Hence, radiotherapy should be discussed as an adjuvant therapy [17], especially in the case of locally advanced cSCC with high recurrence risk or metastatic cSCC. However, in certain settings, it can also be employed as a monotherapy [15"'].

\section{CHEMOTHERAPY AGENTS}

Platin derivates, that is, cisplatin or carboplatin, have been commonly used as the first-line 


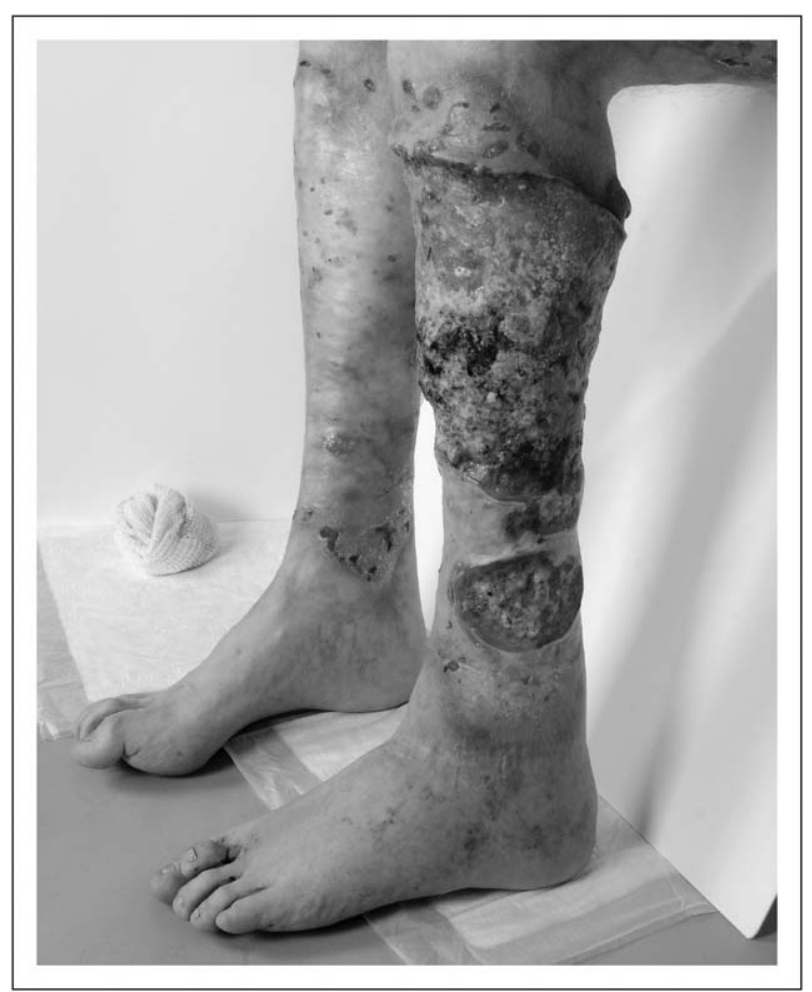

FIGURE 1. Advanced cutaneous squamous cell carcinoma developing on the left leg. Large ulcerated, partially necrotic, local invasive and destructive lesions.

molecules for advanced unresectable or metastatic cSCC but with limited clinical trial experience [18]. A recent single-center report suggested that patients treated with cisplatin benefited with improved

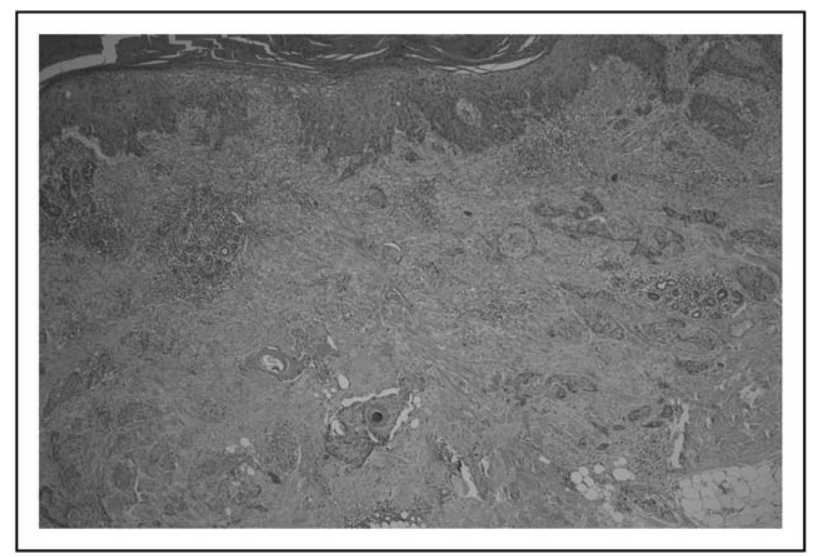

FIGURE 2. Light microscopy studies of a biopsy specimen obtained from an infiltrative growing cutaneous squamous cell carcinoma. Atypical acanthotic epidermis with hyperkeratosis and parakeratosis. Diffuse dermal infiltration of the tumor originating in the epidermis with strands and clusters of cells, focal horn pearl formation and dyskeratotic cells. Several atypical keratinocytes with large eosinophilic cytoplasm, mitoses and marked pleomorphism. response rates (RRs) and survival compared with patients receiving other systemic agents. The study was limited in size and was not randomized [19"]. Other molecules used for either advanced or metastatic disease include 5-fluorouracil (5-FU), bleomycin, methotrexate, adriamycin, taxanes, gemcitabine or ifosfamide alone or in combination [15"']. RRs with single agents vary widely from 17 to $78 \%[20,21]$. Platins and 5-FU are often used as palliative treatment alone or in combination with radiotherapy [22]. Polychemotherapies seem more effective than monochemotherapy but result in more side effects and poor tolerance. There is currently no standard treatment of metastatic disease. Combinations of cisplatin with either 5-FU, doxorubicin or bleomycin have demonstrated some degree of efficacy, achieving complete responses in some cases [23]. The current National Comprehensive Cancer Network guideline suggests cisplatin either alone or in conjunction with 5-FU as first line, but underlines the fact that available data are weak and inconsistent and that newer options should be considered [24].

\section{NOVEL TARGETED THERAPY: EPIDERMAL GROWTH FACTOR RECEPTOR INHIBITORS}

Advanced patient's age, poor general condition or medical comorbidities may preclude the use of conventional chemotherapy $[25,26]$. In this context, the identification of targetable driver mutations important for CSCC progression opens the door to new targeted therapies [27]. Previous studies have shown that up to $80 \%$ of cSCC and $100 \%$ of metastatic cSCC express EGFR [28]. The predictive role of EGFR mutations and EGFR signaling in CSCC is still debated [29,30]. The presence of activating mutations in EGFR itself, elevated EGFR gene copy number and/or aberrant expression of EGFR in tumor cells have been shown to constitute predictive markers of response to EGFR inhibition in clinical trials [31]. Both antibody-based inhibitors of the extracellular domain of EGFR and small molecule inhibitors of intrinsic tyrosine kinase activity are available for targeted therapies.

Two monoclonal EGFR targeting antibiodies have been evaluated in cSCC, cetuximab and panitumumab. Cetuximab is a chimeric monoclonal IgG1 antibody that prevents ligand-induced activation of EGFR and mediates a variety of antitumor activities [32]. So far, the most important study in cSCC is a phase II trial of Maubec et al. [33], in which cetuximab was used as first-line treatment in 36 patients. Disease control could be achieved in 69\% of the intention-to-treat population at week 6 . Two complete remissions and eight partial remissions 
were observed with acceptable skin toxicity. The paucity of controlled trials and the low number of patients described in retrospective case series and single case reports limit the conclusions.

Neoadjuvant therapy with cetuximab alone or in combination with platinum salt and 5-FU have been proposed as a valid option for locally advanced cSCC [34"']. Cetuximab combined with radiotherapy have also shown interesting results in terms of response rate, disease-free survival and overall survival $[35,36]$. Data on combination therapies are reported in Table 1. Panitumumab demonstrated responses in locally advanced cSCC in a phase II study [43]. This treatment has also been employed with success in the case of anaphylaxis after cetuximab [44].

Oral agents targeting the EGFR pathway include gefitinib and erlotinib. Gefitinib, which affects the ATP-binding site of EGFR, inhibits autophosphorylation and receptor activation. A small phase II neoadjuvant study in patients undergoing resection or radiotherapy demonstrated responses [complete and partial responses (PRs) of 18.2 and 27.3\%, respectively] [45]. Treatment with gefitinib appeared well tolerated prior to surgery or combined with radiotherapy, but the role in this context is unclear. Similarly, erlotinib, another orally available EGFR inhibitor, demonstrates responses in advanced cSCC either alone [46] or in combination with other therapies $\left[47,48^{-\cdot}, 49\right]$.

EGFR pathway inhibition is generally well tolerated but generally results in modest disease control in a fraction of patients measured in months [30]. Resistance to EGFR inhibition develops relatively rapidly. The latter may result from several different mechanisms, including increased expression of EGFR, human epidermal growth factor receptor 2 and 3, insulin-like growth factor 1 receptor and tyrosine-protein kinase Met [50]. A mutation in EGFR gene resulting in the substitution P753S and activation of the EGFR kinase domain has been regarded as a biomarker of resistance. Although EGFR expression by tumor cells has been correlated inversely with clinical outcome [51,52], the degree of overexpression does not seem to correlate with the effectiveness of EGFR inhibitors. Better understanding of the EGFR pathway is expected to provide insights useful to design new trials.

\section{OTHER SIGNALING PATHWAYS AND PHARMACOLOGICAL INHIBITORS}

A recent gene set enrichment analysis has highlighted a key role for the MAPK pathway in cSCC [53]. A significant subset of patients treated with either the multikinase inhibitor sorafenib or the BRAF V600E inhibitors vemurafenib and dabrafenib rapidly develop cSCC [54]. Evidence exists indicating that these inhibitors result in a paradoxical activation of the MAPK pathway, which in turn cooperate with mutations in other key oncogenes and tumor suppressors such as H-RAS and TP53 [55]. Hence, it is likely that inhibition of the MAPK pathway provides a potential approach to treat cSCC.

Table 1. Survey of combination therapies with cetuximab for advanced cutaneous squamous cell carcinoma

\begin{tabular}{|c|c|c|c|}
\hline Reference & Sample size & Outcomes & Comments \\
\hline Acevedo-Henao et al. [37] & 36 & $\begin{array}{r}\text { Complete remission } 74 \% \text {, partial } \\
\text { remission } 17 \% \text { and OS } 44.4 \%\end{array}$ & $\begin{array}{l}\text { Cetuximab induction followed by } \\
\text { weekly maintenance until week } 7 \\
\text { together with radiotherapy }\end{array}$ \\
\hline Okano et al. [38] & 22 & Partial remission $82 \%$ & $\begin{array}{l}\text { Cetuximab with concomitant boost } \\
\text { radiotherapy in treatment-naïve } \\
\text { SCC for } 7 \text { weeks }\end{array}$ \\
\hline Knoedler et al. [39] & 84 & $\begin{array}{l}\text { Partial remission } 11 \% \text {, stable disease } \\
50 \% \text {, median OS } 6.7 \text { months }\end{array}$ & $\begin{array}{l}\text { Cetuximab with docetaxel in } \\
\text { recurrent and/or metastatic SCC of } \\
\text { the head and neck }\end{array}$ \\
\hline Bossi et al. [40] & 31 & Well tolerated, improved compliance & $\begin{array}{l}\text { Cetuximab as maintenance after } \\
\text { induction with chemotherapy }\end{array}$ \\
\hline Matuschek et al. [41] & 55 & $\begin{array}{l}\text { Maintenance feasible, with } \\
\text { acceptable toxicity }\end{array}$ & $\begin{array}{l}\text { Cetuximab maintenance (6 months) } \\
\text { after adjuvant concurrent } \\
\text { radiochemotherapy plus cetuximab }\end{array}$ \\
\hline Strojan et al. [42] & 30 & OS $50 \%$, disease-free survival $47 \%$ & $\begin{array}{l}\text { Induction chemotherapy (docetaxel, } \\
\text { cisplatin, 5-fluorouracil) followed } \\
\text { by radiotherapy and weekly } \\
\text { cisplatin and cetuximab }\end{array}$ \\
\hline
\end{tabular}

OS, overall survival. 
ROLE OF IMMUNE SYSTEM IN

CUTANEOUS SQUAMOUS CELL

CARCINOMAS DEVELOPMENT AND

IMMUNOTHERAPY WITH CHECKPOINTS

INHIBITORS

As with most solid tumors, the role of tumor inflammation appears critical to promoting the development of cSCC and may control the growth of established tumors [56]. cSCC is particularly prevalent in patients with chronic sun-exposure as well as in immune suppressed patients, in whom there is up to a 100-fold increased risk of developing cSCC compared with the general population $\left[57,58,59^{-}, 60,61\right]$. Chronic UV exposure results in induction of suppressor $\mathrm{T}$ cells and depletion and down-regulation of Langherans cells $[62,63]$. The tumor microenvironment of cSCC is characterized by a reduced number of peritumoral CD8 ${ }^{+}$cells [64] and increased number of regulatory T cells. Presence of tumor-associated macrophages, IL-10, transforming growth-beta and vascular endothelial growth factor all likely contribute to the immune dysfunction and tumor growth [65-67]. Finally, topical application of imiquimod, which activates toll-like receptors 7 on plasmacytoid dendritic cells, results in secretion of proinflammatory cytokines $[68,69]$ and regression of squamous precancerous lesions [70].

All these observations provide strong rationale for the use of immunotherapy for advanced cSCC. Specifically, checkpoints inhibitors, which are able to activate a T-cell-specific immune response, have shown antitumor activity in different malignancies including malignant melanoma, non small-cell lung cancer and head and neck SCCs [71,72]. However, there are almost no data regarding the use of either the anti-CTLA4 antibody ipilimumab or antiPD-1 agents, such as nivolumab or pembrolizumab, for cSCC [73",74"'].

Since the first positive observation in a 72-yearold patient with metastatic cSCC and melanoma, in which four cycles of ipilimumab resulted in clinical benefit and durable remission with a progressionfree survival of 8 months, there have been other single case reports of adaptive immunotherapy in the form of anti-PD-1 for advanced unresectable or metastatic cSCC (Table 2). We have used anti-PD-1 inhibitors as rescue therapy in five cases with progressing advanced cutaneous squamous cell or basosquamous carcinoma. Our heavily pretreated patients with refractory tumors were given either nivolumab or pembrolizumab and showed clinical benefit including PRs and stable disease. Noteworthy in two cases with PR to anti-PD-1 inhibitors, PD-1L expression failed to reliably predict response. Anti-PD-1 therapy was well tolerated despite multiple comorbidities, including HIV infection. These findings are in line with the reported favorable side-effect profile of anti-PD-1 inhibitors. These observations suggest that immune checkpoint inhibitors may represent a promising new treatment option for aggressive cSCC. Controlled studies are

Table 2. Immunotherapy protocols encompassing immune checkpoint antibodies for treatment of advanced cutaneous squamous cell carcinoma

\begin{tabular}{|c|c|c|c|c|c|c|}
\hline Reference & Cases & Treatment & Drugs & Outcomes & $\begin{array}{c}\text { Progression-free } \\
\text { survival }\end{array}$ & $\begin{array}{l}\text { Significant adverse } \\
\text { events }\end{array}$ \\
\hline Day et al. [73"] & $\begin{array}{l}\text { Lung and liver } \\
\text { metastatic SCC }\end{array}$ & Third line & Ipilimumab & PR & 8 months & Hypophysitis \\
\hline Winkler et al. [74"'] & $\begin{array}{l}\text { Lymph node } \\
\text { metastatic SCC }\end{array}$ & First line & Pembrolizumab & PR & 5 months & None \\
\hline Chang et al. [75"'] & $\begin{array}{l}\text { Locally advanced } \\
\text { SCC }\end{array}$ & Second line & Pembrolizumab & PR & 5 months & $\begin{array}{c}\text { Fatigue, weight loss } \\
\text { and arthralgias }\end{array}$ \\
\hline \multirow[t]{2}{*}{ Lipson et al. [76""] } & $\begin{array}{l}\text { Kidney-transplanted } \\
\text { patient }\end{array}$ & Second line & Pembrolizumab & PR & 8 months & Allograft rejection \\
\hline & Metastatic SCC & & & & & \\
\hline \multirow[t]{4}{*}{ Borradori et al. [77"'] } & Metastatic SCC & Third line & Pembrolizumab & PR & 7 months & $\begin{array}{l}\text { Fatigue, brain } \\
\text { edema }\end{array}$ \\
\hline & $\begin{array}{l}\text { Locally advanced } \\
\text { SCC }\end{array}$ & Fourth line & Pembrolizumab & $\begin{array}{l}\text { Stable } \\
\text { disease }\end{array}$ & 4 months & None \\
\hline & $\begin{array}{l}\text { Locally advanced } \\
\text { SCC }\end{array}$ & Second line & Nivolumab & $\mathrm{PR}$ & 7 months & None \\
\hline & Metastatic SCC & Fourth line & Nivolumab & PR & 6 months & $\begin{array}{c}\text { Fatigue, weight loss, } \\
\text { hyponatremia }\end{array}$ \\
\hline
\end{tabular}

PR, partial response. 
now planned to define the role of checkpoint modulation in management of nonmelanoma skin cancers.

\section{CONCLUSION}

Advanced cSCC remains a challenging disease with poor clinical outcome. In cases of extensive disease with local invasion and/or metastasis, surgery, antineoplasmatic agents and/or radiotherapy are often of limited value and efficacy. Comprehensive genomic profiling with identification of genomic targets and characterization of immunological pathways involved in cSCC development are currently providing the rationale for the development of novel targeted therapies and immunotherapies. The final goal is to optimize clinical outcomes through the effective personalization of treatment.

\section{Acknowledgements}

None.

\section{Financial support and sponsorship}

None.

\section{Conflicts of interest}

There are no conflicts of interest.

\section{REFERENCES AND RECOMMENDED \\ READING}

Papers of particular interest, published within the annual period of review, have been highlighted as:

- of special interest

m. of outstanding interest

1. Karia PS, Han J, Schmults CD. Cutaneous squamous cell carcinoma: estimated incidence of disease, nodal metastasis, and deaths from disease in the United States. J Am Acad Dermatol 2012; 68:957-966.

2. Cheng J, Yan S. Prognostic variables in high-risk cutaneous squamous cell carcinoma: a review. J Cutan Pathol 2016; 43:994-1004.

3. Yu SH, Bordeaux JS, Baron ED. The immune system and skin cancer. Adv Exp Med Biol 2014; 810:182-191.

4. Al-Rohil RN, Tarasen AJ, Carlson JA, et al. Evaluation of 122 advanced-stage

- cutaneous squamous cell carcinoma by comprehensive genomic profiling opens the door for new routes to targeted therapies. Cancer 2016; 122:249-257.

Gene-based therapy for advanced squamous cell carcinoma (SCC)

5. Cao Y, Zhang L, Ritprajakn $\mathrm{P}$, et al. Immunoregulatory molecule $\mathrm{B} 7-\mathrm{H} 1$ (CD274) contributes to skin carcinogenesis. Cancer Res 2011; $71: 24737-24741$

6. Brash DE. UV signature mutations. Photochem Photobiol 2015; 91: $15-26$.

7. Lomas A, Leonardi-Bee J, Bath-Hextall F. A systematic review of worldwide incidence of nonmelanoma skin cancer. Br J Dermatol 2012; 166:10691080.

8. Karia PS, Han J, Schmults CD. Cutaneous squamous cell carcinoma: estimated incidence of disease, nodal metastasis, and deaths from disease in the United States, 2012. J Am Acad Dermatol 2013; 68:957-966.

9. Toll A, Margalef $\mathrm{P}$, Masferrer $\mathrm{E}$, et al. Active nuclear IKK correlates with metastatic risk in cutaneous squamous cell carcinoma. Arch Dermatol Res 2015; 307:721-729.

10. Brunner M, Veness MJ, Ch'ng S, et al. Distant metastases from cutaneous squamous cell carcinoma: analysis of AJCC stage IV. Head Neck 2013; 35:72-75

11. Rotunno R, Marenco F, Ribero S, et al. Electrochemotherapy in nonmelanoma head and neck skin cancers: a three centers experience and literature review. G Ital Dermatol Venereol 2015; 151:610-618.
12. Breuninger $H$, Eigentler $T$, Bootz $F$, et al. Brief $S 2 k$ guidelines - cutaneous squamous cell carcinoma. J Dtsch Dermatol Ges 2013; 11 (Suppl 3):37-45; $39-47$.

13. Weinberg AS, Ogle CA, Shim EK. Metastatic cutaneous squamous cell carcinoma: an update. Dermatol Surg 2007; 33:885-899.

14. Jambusaria-Pahlajani $A$, Miller $C J$, Quon $H$, et al. Surgical monotherapy versus surgery plus adjuvant radiotherapy in high-risk cutaneous squamous cell carcinoma: a systematic review of outcomes. Dermatol Surg 2009; 35:574-585.

15. Stratigos A, Garbe $C$, Lebbe $C$, et al. Diagnosis and treatment of invasive

- squamous cell carcinoma of the skin: European consensus-based interdisciplinary guideline. Eur J Cancer 2015; 51:1989-2007.

Recent review on treatment and diagnosis of SCC.

16. Veness MJ, Morgan GJ, Palme CE, et al. Surgery and adjuvant radiotherapy in patients with cutaneous head and neck squamous cell carcinoma metastatic to lymph nodes: combined treatment should be considered best practice. Laryngoscope 2005; 115:870-875.

17. Chen AM, Grekin RC, Garcia J, et al. Radiation therapy for cutaneous squamous cell carcinoma involving the parotid area lymph nodes: dose and volume considerations. Int J Radiat Oncol Biol Phys 2007; 69:13771380.

18. Jarkowski $A$, Hare $R$, Loud $P$, et al. Systemic therapy in advanced cutaneous squamous cell carcinoma (CSCC): the Roswell Park experience and a review of the literature. Am J Clin Oncol 2014; 39:545-548.

19. Trodello $C$, Pepper JP, Wong $M$, et al. Cisplatin and cetuximab treatment for

metastatic cutaneous squamous cell carcinoma: a systematic review. Dermatol Surg 2016; 43:40-49.

Evidence-based research on cisplatin in SCC, the classical therapy.

20. Sadek H, Azli N, Wendling JL, et al. Treatment of advanced squamous cell carcinoma of the skin with cisplatin, 5-fluorouracil, and bleomycin. Cancer 1990; 66:1692-1696

21. Suzuki TIY, Kuramochi $A$, Kiyohara $Y$, et al. Squamous cell carcinoma and basal cell carcinoma. Gan To Kagaku Ryoho 1997; 24:16-22.

22. Khansur T, Kennedy A. Cisplatin and 5-fluorouracil for advanced locoregional and metastatic squamous cell carcinoma of the skin. Cancer 1991; 67:2030-2032

23. DeConti RC. Chemotherapy of squamous cell carcinoma of the skin. Semin Oncol 2012; 39:145-149.

24. Bichakjian $C$, Alam M, Andersen J, et al. National Comprehensive Cancer Network Clinical Practice Guidelines in Oncology: practice guidelines for nonmelanoma skin cancer. 2013; http://antoniorondonlugo.com/blog/wpcontent/uploads/2014/03/ca-basocelular-y-epidermoide- Dr-Gomez-reza.pdf. [Cited 6 February 2016; Accessed 12 December 2015]

25. Wollina U. Nonmelanoma skin cancer on the rise. J Cutan Aesthet Surg 2012; $5: 11$.

26. Conen KL, Fischer N, Hofbauer GF. Cetuximab in metastatic squamous cell cancer of the skin: a Swiss case series. Dermatology 2014; 229:97-101.

27. Pickering $\mathrm{CR}$, Zhou JH, Lee JJ, et al. Mutational landscape of aggressive cutaneous squamous cell carcinoma. Clin Cancer Res 2014; 20:65826592.

28. Galer CE, Corey CL, Wang Z, et al. Dual inhibition of epidermal growth factor receptor and insulin-like growth factor receptor I reduces angiogenesis and tumor growth in cutaneous squamous cell carcinoma. Head Neck 2011; 33:189-198.

29. Ciardiello F, Tortora G. EGFR antagonists in cancer treatment. N Engl J Med 2008; 358:1160-1174.

30. Modjtahedi H, Essapen S. Epidermal growth factor receptor inhibitors in cancer treatment: advances, challenges and opportunities. Anticancer Drugs 2009; 20:851-855

31. Cohen EE, Kane MA, List MA. Phase II trial of gefitinib $250 \mathrm{mg}$ daily in patients with recurrent and/or metastatic squamous cell carcinoma of the head and neck. Clin Cancer Res 2005; 11:8418-8424.

32. Dittman K, Mayer C, Rodemann HP. Inhibition of radiation-induced EGFR nuclear import by C225 (Cetuximab) suppresses DNA-PK activity. Radiother Oncol 2005; 76:157-161.

33. Maubec E, Petrow $P$, Scheer-Senyarich I, et al. Phase II study of cetuximab as first-line single-drug therapy in patients with unresectable squamous cell carcinoma of the skin. J Clin Oncol 2011; 29:3419-3426.

34. Reigneau $M$, Robert $C$, Routier $E$, et al. Efficacy of neoadjuvant cetuximab

- alone or with platinum salt for the treatment of unresectable advanced nonmetastatic cutaneous squamous cell carcinomas. Br J Dermatol 2015; 173:527-534

Neoadjuvant treatment for adjuvant SCC.

35. Preneau S, Rio E, Brocard A, et al. Efficacy of cetuximab in the treatment of squamous cell carcinoma. J Dermatolog Treat 2014; 25:424-427.

36. Samstein RM, Ho AL, Lee NY. Locally advanced and unresectable cutaneous squamous cell carcinoma: outcomes of concurrent cetuximab and radiotherapy. J Skin Cancer 2014; 2014:284582.

37. Acevedo-Henao CM, Valette $G$, Miglierini $P$ et al. Radiotherapy combined with cetuximab for locally advanced head and neck cancer: results and toxicity. Cancer Radiother 2012; 16:601-603.

38. Okano $\mathrm{S}$, Yoshino $\mathrm{T}$, Fujii $\mathrm{M}$, et al. Phase II study of cetuximab plus concomitant boost radiotherapy in Japanese patients with locally advanced squamous cell carcinoma of the head and neck. Jpn J Clin Oncol 2013; 43:476-482. 
39. Knoedler M, Gauler TC, Gruenwald V, et al. Phase II study of cetuximab in combination with docetaxel in patients with recurrent and/or metastatic squamous cell carcinoma of the head and neck after platinum-containing therapy: a multicenter study of the Arbeitsgemeinschaft Internistische Onkologie. Oncology 2013; 84:284-289.

40. Bossi P, Kornek G, Lanzetta G, et al. Safety and feasibility of every-other-week maintenance cetuximab after first-line chemotherapy in patients with recurrent or metastatic head and neck squamous cell cancer. Head Neck 2013; 35:1471-1474.

41. Matuschek $C$, Bölke $E$, Belka $C$, et al. Feasibility of 6-month maintenance cetuximab after adjuvant concurrent chemoradiation plus cetuximab in squamous cell carcinoma of the head and neck. Strahlenther Onkol 2013; 189:625-631.

42. Strojan P, Grašič Kuhar C, et al. TPF induction chemotherapy and concomitant irradiation with cisplatin and cetuximab in unresectable squamous cell carcinoma of the head and neck. Head Neck 2014; 36:1555-1561.

43. Foote MC, McGrath M, Guminski $A$, et al. Phase II study of single-agent panitumumab in patients with incurable cutaneous squamous cell carcinoma. Ann Oncol 2014; 25:2047-2052.

44. Marti A, Fauconneau A, Ouhabrache N, et al. Complete remission of squamous cell carcinoma after treatment with panitumumab in a patient with cetuximab-induced anaphylaxis. JAMA Dermatol 2016; 152:343-345.

45. Lewis CM, Glisson BS, Feng L, et al. A phase II study of gefitinib for aggressive cutaneous squamous cell carcinoma of the head and neck. Clin Cancer Res 2012; 18:1435-1446.

46. Engelhardt $\mathrm{C}$, Curiel-Lewandrowski $\mathrm{C}$, Warneke J, et al. Metastatic cutaneous squamous cell carcinoma responding to erlotinib therapy. J Am Acad Dermatol 2011; 65:237-238.

47. Macripò G, Caliendo V, Grassi M, et al. Squamous cell carcinoma of the umbilicus: management of an unusual localization. Tumori 2011; 97:236-238.

48. Read WL, Brumund KT, Weisman RA, et al. Squamous cell carcinomas of the

m. skin responsive to erlotinib: 5 cases. JAAD Case Rep 2015; 1:153-156.

Interesting case series of SCCs treated with erlotinib.

49. Cranmer LD, Engelhardt C, Morgan SS. Treatment of unresectable and metastatic cutaneous squamous cell carcinoma. Oncologist 2010; 15:1320-1328.

50. Wheeler DL, Huang S, Kruser TJ, et al. Mechanisms of acquired resistance to cetuximab: role of HER (ErbB) family members. Oncogene 2008; 27:39443956.

51. Modjtahedi H, Dean C. The receptor for EGF and its ligands: expression, prognostic value and target for therapy in cancer. Int J Oncol 1994; 4:277296.

52. Nicholson RI, Gee JMW, Harper ME. EGFR and cancer prognosis. Eur J Cancer 2001; 37:9-15.

53. Lambert SR, Mladkova N, Gulati $A$, et al. Key differences identified between actinic keratosis and cutaneous squamous cell carcinoma by transcriptome profiling. Br J Cancer 2014; 110:520-529.

54. Ribas A, Flaherty KT. BRAF targeted therapy changes the treatment paradigm in melanoma. Nat Rev Clin Oncol 2011; 8:426-433.

55. Cammareri $P$, Rose AM, Vincent DF, et al. Inactivation of TGFb receptor in stem cells drives cutaneous squamous cell carcinoma. Nat Commun 2016; 7:12493.

56. Gajewski TF, Schreiber H, Fu YX. Innate and adaptive immune cells in the tumor microenvironment. Nat Immunol 2013; 14:1014-1022.

57. Freeman $A$, Bridge JA, Maruthayanar $P$, et al. Comparative immune phenotypic analysis of cutaneous squamous cell carcinoma and intraepidermal carcinoma in immune-competent individuals: proportional representation of CD8 $+\mathrm{T}$ cells but not FoxP3 + regulatory T-cells is associated with disease stage. PLoS One 2014; 9:e110928.

58. Kim Y, He YY. Ultraviolet radiation-induced nonmelanoma skin cancer: regulation of DNA damage repair and inflammation. Genes Dis $2014 ; 1: 188-198$.
59. Chockalingam $R$, Downing $C$, Tyring SK. Cutaneous squamous cell carcino-

- mas in organ transplant recipients. J Clin Med 2015; 4:1229-1239.

Uptodate review on molecular, clinical and management of SCC in transplanted patients.

60. Marcil I, Stern RS. Risk of developing a subsequent nonmelanoma skin cancer in patients with a history of nonmelanoma skin cancer: a critical review of the literature and meta-analysis. Arch Dermatol 2000; 136:15241530.

61. O'Donovan $P$, Perrett $C M$, Zhang $X$, et al. Azathioprine and UVA light generate mutagenic oxidative DNA damage. Science 2005; 309:1871-1874.

62. Ullrich SE. Mechanisms underlying UV-induced immune suppression. Mutat Res 2005; 571:185-205

63. Moens U, Van Ghelue M, Ehlers B. Are human polyomaviruses co-factors for cancers induced by other oncoviruses? Rev Med Virol 2014; 24:343-360; Epub 2014 Jun 2.

64. Boukamp P. Nonmelanoma skin cancer: what drives tumor development and progression? Carcinogenesis 2005; 26:1657-1667.

65. Smyth MJ, Dunn GP, Schreiber RD. Cancer immunosurveillance and immunoediting: the roles of immunity in suppressing tumor development and shaping tumor immunogenicity. Adv Immunol 2006; 90:1-50.

66. Tjiu JW, Chen JS, Shun CT, et al. Tumor-associated macrophage-induced invasion and angiogenesis of human basal cell carcinoma cells by cyclooxygenase-2 induction. J Invest Dermatol 2009; 129:1016-1025.

67. Pettersen JS, Fuentes-Duculan J, Suarez-Farinas M, et al. Tumor-associated macrophages in the cutaneous SCC microenvironment are heterogeneously activated. J Invest Dermatol 2011; 10:10.

68. Woodmansee C, Pillow J, Skinner RB Jr. The role of topical immune response modifiers in skin cancer. Drugs 2006; 66:1657-1664.

69. De Giorgi V, Salvini C, Chiarugi A, et al. In vivo characterization of the inflammatory infiltrate and apoptotic status in imiquimod-treated basal cell carcinoma. Int J Dermatol 2009; 48:312-321.

70. Torres A, Storey L, Anders M, et al. Immune-mediated changes in actinic keratosis following topical treatment with imiquimod 5\% cream. J Transl Med 2007; 5:7.

71. Seiwert TY, Haddad RI, Gupta S, et al. Antitumor activity and safety of pembrolizumab in patients (pts) with advanced squamous cell carcinoma of the head and neck (SCCHN): preliminary results from KEYNOTE-012 expansion cohort. J Clin Oncol 2015; 33:. (suppl; abstr LBA6008).

72. Formenti SC, Demaria S. Systemic effects of local radiotherapy. Lancet Oncol 2009; 10:718-726.

73. Day F, Kumar M, Fenton L, Gedye C. Durable response of metastatic

squamous cell carcinoma of the skin to ipilimumab immunotherapy. J Immunother $2017 ; 40: 36-38$.

Successful treatment with ipilimumab in SCC

74. Winkler JK, Schneiderbauer R, Bender C, et al. Antiprogrammed cell death-1

m. therapy in nonmelanoma skin cancer. Br J Dermatol 2016. [Epub ahead of print]

Successful treatment with anti-PD-1 in SCC.

75. Chang ALS, Kim J, Luciano R, et al. A case report of unresectable cutaneous

-1. squamous cell carcinoma responsive to pembrolizumab, a programmed cell death protein 1 inhibitor. JAMA Dermatol 2016; 152:106-107.

Successful treatment with anti-PD-1 in SCC.

76. Lipson EJ, Bagnasco SM, Moore J, et al. Tumor regression and allograft

-1. rejection after administration of anti-PD1. N Engl J Med 2016; 374:896-898.

Successful treatment with anti-PD-1 in SCC.

77. Borradori L, Sutton B, Shayesteh P, Daniels GA. Rescue therapy with

- antiprogrammed cell death protein 1 inhibitors of advanced cutaneous squamous cell carcinoma and basosquamous carcinoma: preliminary experience in five cases. Br J Dermatol 2016; 175:1382-1386. doi: 10.1111/ bjd. 14642 .

Clinical series of advanced SCC successfully treated with anti-PD-1. 